\title{
Avaliação do Serviço de Atenção Domiciliar em Maranguape - Ceará: Um Olhar na Perspetiva dos Usuários, Profissionais e Gestores do Serviço
}

\author{
Cleovânia Fontenele dos Santos ${ }^{1}$ \\ Jadson Franco ${ }^{2}$ \\ ${ }^{1}$ Escola de Saúde Pública do Ceará/ESP-CE, Brasil; E-Mail: cleovanianutri@gmail.com \\ 2Fundação Osvaldo Cruz, Brasil; E-Mail: jadsonpsic@hotmail.com
}

\begin{abstract}
Resumo
Este artigo buscou avaliar o serviço de atenção domiciliar do município de Maranguape através da percepção dos usuários, profissionais e gestores do serviço. Um estudo descritivo de abordagem qualitativa, com coleta de dados nos meses de novembro e dezembro de 2016; através de entrevistas individuais, com instrumento semiestruturado. O método de análise foi através do conteúdo do discurso, classificados por categorias. O serviço de atenção domiciliar é visto como uma forma diferenciada e ampliada de cuidado; com práticas de efetivação da atenção integral. A análise do acolhimento humanizado apontou que o primeiro contato deve apresentar uma escuta qualificada. Nota-se que o financiamento é o nó crítico para execução do serviço com qualidade; a deficiência na estrutura dificulta garantir o acesso. O reconhecimento do domicílio como um espaço de recuperação de saúde facilita os vínculos e corresponsabilidades. Recomenda-se que os profissionais e gestores busquem ferramentas adequadas para incorporação de novas técnicas.
\end{abstract}

Palavras-chave: acolhimento em saúde; assistência à saúde; atenção domiciliar; humanização.

\begin{abstract}
This article aimed to evaluate the home care service of the municipality of Maranguape through the perception of users, professionals and managers of the service. A descriptive study of a qualitative approach, with data collection in the months of November and December of 2016 was performed, with a semi-structured instrument and individual interviews. The chosen method of analysis was the content of the discourse, classified by categories. Home care service is seen as a different and expanded form of care; with effective practices of integral attention. User embracement analysis of the service pointed out that the first contact should have a qualified listening. It is noted that financing is a critical point for the execution of quality service and the deficiency in the structure makes it difficult to guarantee access. The perception of the home as a health recovery space facilitates the bonds and coresponsibilities. It is recommended that professionals and managers seek appropriate tools to incorporate new techniques.
\end{abstract}

Keywords: health care; home care; humanization. 


\section{Introdução}

As transformações ocorridas na área da saúde fazem repensar novas formas de cuidado, com modalidades diferenciadas, pensando na melhoria do acesso, fluxos, integralidade da assistência, bem estar do usuário, assim como na viabilidade e sustentabilidade econômica do Sistema Único de Saúde (SUS).

O Serviço de Atenção Domiciliar - SAD é substitutivo ou complementar à internação hospitalar ou atendimento ambulatorial, responsável pelo gerenciamento e operacionalização das Equipes Multiprofissionais de Atenção Domiciliar (EMAD) e Equipes Multiprofissionais de Apoio (EMAP).

De acordo com a portaria $n^{\circ} 963$ de 27 de maio de 2013, a atenção domiciliar é uma nova modalidade de atenção à saúde, substitutiva ou complementar às já existentes, caracterizada por um conjunto de ações de promoção à saúde, prevenção e tratamento de doenças e reabilitação prestadas em domicílio, com garantia de continuidade de cuidados e integrada às redes de atenção à saúde (BRASIL, 2013).

Nesse sentido, a Atenção Domiciliar tem como objetivo a reorganização do processo de trabalho das equipes que prestam cuidado domiciliar na atenção básica, ambulatorial, nos serviços de urgência e emergência e hospitalar, com vistas à redução da demanda por atendimento hospitalar e/ou redução de período de permanência de usuários internados, a humanização da atenção, a desinstitucionalização e a ampliação da autonomia dos usuários.

Refletindo sobre essa necessidade, Andreazzi e Baptista (2007) compreendem que a Atenção Domiciliar tem um propósito de otimizar o cuidado com um olharampliado, que engloba uma série de cuidados heterogênicos, com combinações de tecnologias leves e duras no plano de cuidado.

A implantação do Serviço de Atenção Domiciliar em Maranguape ocorreu em 04 de abril de 2012 com o objetivo de instituir modalidades substitutivas de cuidado, que possibilitassem a redução de internação hospitalar e oferecesse conforto ao usuário em domicílio.

O serviço é constituído por uma Equipe Multiprofissional de Atenção Domiciliar EMAD Tipo 1, contando com profissional médico, enfermeiro e técnico de enfermagem; além de uma Equipe Multiprofissional de Apoio EMAP, contando com profissional nutricionista, fisioterapeuta e assistente social. Atende um território de aproximadamente 122.000 habitantes. Os usuários são os que recebem alta hospitalar, da Unidade de Pronto Atendimento ou são referenciados pelas equipes da atenção primária. O serviço atende em média 60 (sessenta) usuários por mês, de segunda a sexta feira, no período de 08:00 às 16:00 horas; com frequência de visitas semanais, quinzenais e/ou mensais, estabelecidas de acordo com a condição de saúde do paciente. No período noturno, feriados e finais de semana não há cobertura física da equipe. Caso necessitem de assistência, os pacientes são orientados pelo contato telefônico para encaminhamentos e condutas necessárias.

O interesse pela temática surgiu em decorrência da experiência como residente em saúde coletiva, por meio do percurso às redes de atenção, tendo o SAD como dispositivo no campo de prática profissional. Atuando na articulação dos processos em saúde, atenção domiciliar, protocolos de encaminhamentos e educação permanente; podendo vivenciar e entender o funcionamento e relacionamento das redes. No decorrer desse percurso surgiram algumas inquietações sobre o acesso, a integralidade, assistência, fragilidades e desafios desencadeados por esta modalidade, problematizando as redes concretas que dialogam com a potência da atenção domiciliar no enfrentamento destes desafios.

Como pesquisadora motivada em contribuir com o aperfeiçoamento do serviço de atenção domiciliar, algumas questões me despertam e me impulsionam a buscar respostas. Portanto, conhecer e refletir sobre as opiniões dos atores envolvidos no serviço é de extrema relevância, levando ao aprofundamento das questões envolvidas nesse processo avaliativo.

Esta pesquisa propôs avaliar o serviço de atenção domiciliar através da análise do discurso da percepção dos usuários, profissionais e gestores envolvidos no serviço, identificando as potencialidades e fragilidades, a comunicação com a rede e as mudanças de práticas de trabalho decorrentes da implantação do serviço de atenção domiciliar. 
Assim, a pesquisa pôde contribuir para elucidações a respeito da legitimidade do serviço, no tocante ao acesso em redes, da comunicação, das relações interpessoais, assim como evidenciar as potencialidades e fragilidades na visão dos atores implicados; e fornecer subsídios que possibilitem reformulações e readequações nas articulações do serviço.

\section{Metodologia}

Trata-se de uma pesquisa por meio de estudo descritivo de abordagem qualitativa, que utiliza como instrumento de coleta de dados um roteiro de entrevista semiestruturado aplicado em entrevistas individuais, gravação e transcrição do discurso dos atores envolvidos na pesquisa. A Coleta ocorreu no município de Maranguape, nos meses de novembro e dezembro do ano de 2016. $O$ estudo atende a quatro características centrais: particularidade, descrição, descoberta (heurística) e a indução. Para avaliação do serviço de atenção domiciliar, seu funcionamento, percepção do serviço, possibilidades de intervenção, nível de satisfação para com o serviço, estruturação, se fez necessário análise do discurso dos usuários (seis), dos cuidadores (vinte e cinco) quando os pacientes encontravamse impossibilitados, dos profissionais da equipe multiprofissional da atenção domiciliar (sete) e dos gestores do serviço (dois); totalizando quarenta participantes. A definição do número de sujeitos levou em consideração o universo de pacientes atendidos pelo serviço e o fechamento amostral por saturação teórica, definido como a suspensão de inclusão de novos participantes quando os dados obtidos passam a apresentar, na avaliação do pesquisador, uma certa redundância ou repetição. Para identificação das categorias entrevistadas utilizou-se códigos; para os usuários a letra (U), cuidador (C), profissionais (E) e gestão (G) com numeração de acordo com a ordem da entrevista. Permitiu-se uma conversação entre o pesquisador e o entrevistado, propiciando ao primeiro a aproximação e seleção dos elementos pertinentes ao cumprimento de seus objetivos e, ao segundo, o pronunciamento livre, embora direcionado, sobre a temática em questão. A análise dos dados qualitativos das perguntas do questionário das entrevistas foi sistematizada pela análise de discurso (Orlandi, 2001) e organizada por categorias de análises associados aos sentidos das falas e seu significado no processo formativo. As questões norteadoras foram divididas em três instrumentos diferentes para cada grupo entrevistado e foram divididas nas seguintes categorias: Acolhimento Humanizado, Financiamento na Atenção Domiciliar, Domicílio como Espaço de Recuperação e Atenção Domiciliar dialogando com a Rede. A pesquisa foi aprovada no Comitê de Ética da Escola de Saúde Pública do Ceará por meio de parecer número: CAAE 61828216.6.0000.5037.

\section{Resultados e Discussão}

\subsection{Organização da Saúde de Maranguape}

O município de Maranguape localiza-se a $25 \mathrm{~km}$ de Fortaleza e faz parte da região metropolitana do referido município, com uma população estimada em 122.000 habitantes, com a ocupação de uma área de $591 \mathrm{~km}^{2}$ a 67 metros de altitude em relação ao nível do mar (IBGE, 2014).

O Município é habilitado à forma de Gestão Plena do Sistema de Saúde. E apresenta uma diversidade de serviços implantados. As Unidades Básica de Saúde - UBS/ Equipe Saúde da Família - ESF propõe-se, para sua área de abrangência, como porta de entrada do Sistema Municipal de Saúde, ficando pactuado que cada UBS/USF é responsável pelos riscos e agravos à saúde que ocorram em sua área, devendo ser capaz de identificar os problemas de saúde mais relevantes, quais os indivíduos ou grupos mais suscetíveis ao risco de adoecer e/ou morrer, assim como planejar e executar ações mais adequadas para o seu enfrentamento. Fica sob sua responsabilidade a articulação com os diversos pontos de atenção e equipamentos sociais, tais como: escolas, creches, asilos, associações, domicílio, ambientes de trabalho, etc., que estejam localizadas em sua área de abrangência.

A Rede de Atenção à Saúde do Município de Maranguape é constituída por: trinta equipes de saúde; vinte e duas unidades básicas de saúde; treze unidades de apoio; uma unidade de pronto atendimento 24 horas - UPA, de complexidade intermediária; uma policlínica; dois hospitais, sendo um público e um privado; três centros de apoio psicossocial (CAPS), sendo um CAPS geral, um CAPS AD e um CAPS infantil, todos concentrados na sede. Para apoiar esses serviços, o município dispõe de duas equipes de Nasf - Núcleo de Apoio a Saúde da Família e 01 - Equipe Multiprofissional de Atenção Domiciliar - EMAD Tipo 1 e 01 Equipe Multiprofissional de Apoio - EMAP. 
A reorganização da rede básica apresenta a reversão à centralidade do hospital e da atenção individual, permitindo um processo gradativo de desospitalização, e fortalecendo o cuidado e assistência que deve e podem ser absorvidas pela rede básica de saúde, considerando o seu poder de resolutividade.

\section{Acolhimento Humanizado}

Embora a palavra "humanizar" tenha vários significados, nos dias de hoje, o termo ganha, no campo da saúde, uma conotação de reavaliação de valores morais e éticos que, de certa forma, foram esquecidos ou se perderam nas práticas dos serviços. Apesar de tantos avanços na área da saúde e no cotidiano dos serviços envolvendo formação, gestão, trabalhadores e usuários, devemos, inicialmente, refletir sobre os diversos significados da humanização nesse contexto, bem como seus reflexos para a sociedade e a para saúde (Souza, 2008).

O conceito de humanização, portanto, quando relacionado à saúde, ganha muitos significados e uma dimensão ampliada. Para Pucinni e Cecílio (2004), a humanização possui um movimento dinâmico constituído de desejos, de atitudes e de comportamentos, na procura por um modelo de satisfação. Desse modo, os diferentes caminhos trilhados irão resultar em um reconhecimento das relações interpessoais como fator de fortalecimento, na luta pela dignidade humana no atendimento em saúde.

De certa forma, tem-se percorrido caminhos tortuosos à procura da humanização, uma vez que a compreensão que os trabalhadores da área da saúde têm sobre o que seja atendimento humanizado quase sempre é bastante influenciada pela educação e meio social a que pertencem (Schweller, 2014).

Schweller (2014), ao tratar especificamente da situação vivida pelos médicos, explica, entre outros pontos abordados em seu estudo, que os exemplos negativos recebidos durante a faculdade moldam o caráter dos futuros médicos. Este estudo afirma que o perfil dos alunos que ingressam no curso demonstra superproteção e pouca experiência com fracasso ou perda. Segundo o mesmo, a sociedade produziu uma geração que cresce com pouca capacidade de comunicação pelo confinamento em casa e por nunca terem sido expostos a situações de pobreza e doença. Dessa forma, usam o distanciamento afetivo do paciente como um mecanismo de defesa.

O Sistema indica que é direito da população um atendimento integral, que intervenha tanto nas ações individuais de tratamento, quanto nas ações coletivas de prevenção e promoção de saúde (Brasil, 2009).

O acolhimento significa uma escuta qualificada, uma ação de aproximação, de estar com o outro, ou seja, uma atitude de inclusão, de estar em relação com algo ou alguém. É visto como uma tecnologia leve, de comunicação em equipe, na relação com o usuário, que se propõe a inverter a lógica de organização e funcionamento do serviço de saúde, partindo dos seguintes princípios: garantir acessibilidade universal, reorganizar o processo de trabalho com base em uma equipe multiprofissional e qualificar a relação trabalhador usuário (Franco, Bueno, \& Merhy, 2000).

Configura-se como uma diretriz ética, estética e política da Política Nacional de Humanização do SUS. Ética, no que diz respeito ao compromisso com o outro, na atitude de acolhê-lo em sua dimensão, com suas peculiaridades de dores, alegrias, modos de viver, sentir e viver a vida (BRASIL, 2009).

$\mathrm{Na}$ atenção domiciliar, o acolhimento representa uma postura sentimental, na lógica de que a equipe se insere no meio de convívio do paciente, conhecendo sua realidade, percebendo suas particularidades, entendendo a dor e o sofrimento em todas as suas facetas (Brasil, 2013). Compreende-se que a construção de relações de vínculo e afeto inicia no acolhimento, daí a importância da qualidade do atendimento nesse primeiro contato com o usuário.

Logo, com uma escuta qualificada é possível garantir o acesso oportuno desses usuários a tecnologias adequadas às suas necessidades, ampliando a efetividade das práticas de saúde. É assegurado que todos sejam atendidos com prioridades a partir da avaliação de vulnerabilidade, gravidade e risco. Por outro lado, fazendo uma análise da clínica ampliada, observa-se que existe uma percepção dos afetos produzidos na relação clínica durante o acolhimento e uma qualificação no diálogo de modo a possibilitar decisões compartilhadas.

Para Maynart et al., (2014) a escuta qualificada quando é feita com eficiência possui potencial terapêutico, por conseguir acessar o campo humano subjetivo, melhorando a condição e expressão do usuário. 
Para questões contextuais sobre acolhimento, os usuários abordados pela pesquisa manifestam satisfação e identificam o acolhimento humanizado de formas distintas, na qual defendem a ideia que é ser escutado, respeitado e orientado sobre suas necessidades diante da complexidade em que vivem. Sentimentos percebidos e validados nos discursos:

"Ser bem acolhido é ser bem cuidado" (U1); “É quando agente faz uma pergunta e responde direitinho" (C19); "Agente ter pessoas que possam ouvir os nossos filhos" (C20).

Em relação às expectativas do acolhimento, os discursos dos usuários se aproximam das ideias apresentados por Cotta et al. (2005), onde reconhece que o cuidado recebido deve basear-se na paciência, no diálogo, na atenção e no respeito. "É respeitar o que eu digo, né? a pessoa ter atenção com a gente" (U4).

Acolher compreende uma postura de escuta das ansiedades, angústias e necessidades da pessoa e de seus familiares, de forma a tornar o processo de trabalho/cuidado mais humano, a partir do momento que centra seu foco no outro (Roa et al., 2009). "A recepção que o profissional traz junto à família da gente; porque tem o paciente e a cuidadora" (C12).

“'É a maneira que somos atendidos, escutarem e darem orientação de como devo agir com o paciente" (C14). Na literatura, muitos estudiosos salientam que os cuidadores precisam de maior suporte das equipes, dando apoio à família e ao cuidador, conhecer os recursos disponíveis da família e da comunidade, levando em consideração que a permanência no domicílio não é integral; e na maioria dos casos a família é que assume o papel de cuidador diário. Por esta razão, precisam de apoio e orientação para exercer a função (Brasil 2012). “[...] me sinto bemvendo a equipe me orientando, quanto mais orientação melhor" (C15).

Diante destas falas, Brasil (2008) reitera que o acolhimento busca estabelecer vias de diálogo para a resolução dos problemas individuais, ampliando a ação interventora dos profissionais de saúde no SUS e contemplando o princípio da universalidade.

Por outro lado, a manifestação de dois usuários demonstrou desconhecimento da proposta do acolhimento pela comunidade, definindo-o como ações de "... é vir aqui e renovar minhas receitas" (C3); "é visitar de quinze em quinze dias" (C1); distanciando cada vez mais da integralidade no serviço; dando espaço para reflexão da construção e execução da acolhida nesses territórios. Entende-se que o acolhimento vai além de uma relação clínica, se incorpora como um apoio transversal. É importante tornar claro para o usuário a sua autonomia enquanto protagonista da sua saúde.

Ao serem questionados sobre acolhimento humanizado, alguns profissionais enfatizaram a relação com o paciente e a forma como a equipe se comporta no processo saúde-doença. "Em primeiro lugar ouvir o paciente, saber o que ele traz para você e respeitar as vontades dele, a cultura dele" (E2). Assemelha-se com a proposta da Política Nacional de Humanização que é reconhecer o que o outro traz como legítima e singular necessidade de saúde. "Pra mim acolhimento humanizado é quando você tem uma equipe multiprofissional que trata de maneira global e não isolado" (E4). [...] É atendimento coletivo" (E3).

Nessa linha de pensamento o acolhimento deve comparecer e sustentar as relações; sendo construido de forma coletiva, a partir da análise dos processos de trabalho, tendo como objetivo a construção de relações de confiança, compromisso e vínculo entre as equipes/serviços, trabalhador/equipes e usuário com sua rede socioafetiva “... é tratá-lo da melhor forma possível, não só como enfermeira, mas como um amigo, uma pessoa que está ali para ajudar" (E5). [...] "Recepcionar bem, ser educado para com o próximo" (E3).

Identifica-se na fala deste trabalhador a importância do acolhimento na atenção primária enquanto dispositivo capaz de gerar corresponsabilidade e autonomia "o acolhimento faz parte dos princípios da atenção primária [...] é ver o paciente de forma holística, pensando na sua qualidade de vida" [...] é não centrar os problemas da pessoa apenas na doença, mas em todos os aspectos relacionados a família, com a sociedade e comunidade" (E1). Em estudos como o de Rocha et al. (2008) o acolhimento e o vínculo estão entre as dimensões do cuidado mais bem avaliados por usuários, gestores e profissionais.

Conforme foi analisado, a comunicação é um dos aspectos primordiais para o entendimento da essência do acolhimento, partindo do princípio que tal processodeve favorecer a estruturação de uma relação entre trabalhadores e usuários que favoreça a autonomia do usuário. "É você se dedicar e não medir esforços para ajudar" 
(E5). Além de atitudes simples e de respeito para com o outro, de solidariedade, de confiança e de atenção individualizada no acolhimento são cuidados que resgatam a humanização do atendimento "é respeitar sua cultura, seu grau de instrução e conhecimento" (E2).

A percepção da gestão corrobora a ideia dos profissionais sobre o termo acolhimento quando destaca em seu discurso a integralidade na atenção. "É aquele que você procura se colocar no lugar do paciente, fazendo uma escuta que o paciente realmente necessita" (G1) [...] "não tratar o paciente como mais um" (G2) e [...] "avalia na sua integralidade" (G1).

A sensibilidade dos gestores na perspectiva do acolhimento, de entender sua importância enquanto ferramenta do processo de trabalho fortalece e fomenta a inovação e/ou inserção de profissionais diferenciados no modo de cuidar. Outro fator importante citado é ver no acolhimento um momento de compressão da situação de saúde e necessidade do paciente; bem como fazer os direcionamentos necessários e resolutivos utilizando os níveis de atenção disponíveis na rede de atenção à saúde, como é salientado nessa fala "... direciona o melhor canto para $a$ resolução, é um acolhimento que você dar resolução" (G2). Portanto, deve ser visto como uma atenção com resolutividade em tempo oportuno.

\section{Financiamento na Atenção Domiciliar}

O processo de descentralização da saúde em que os municípios foram levados à condição de gestores do Sistema Único de Saúde (SUS), e responsáveis pela execução de todas as ações e os serviços de saúde em seu território deixou o gestor municipal com autonomia para o planejamento da política local, seu orçamento e execução, controle e sua avaliação.

Seguindo essa linha de pensamento, o Ministério da Saúde planeja e orienta as políticas, buscando o financiamento dos programas e estratégias de forma tripartite.

Na Portaria 963 de 27 de maio de 2013 fica instituído um incentivo de custeio mensal para manutenção do SAD, que é repassado mensalmente do Fundo Nacional de Saúde para o fundo de saúde do ente federativo beneficiário (BRASIL, 2013). Além de que no Art. 41 ressalta-se que a eventual complementação dos recursos financeiros repassados pelo Ministério da Saúde para o custeio das ações do SAD é de responsabilidade conjunta dos Estados, do Distrito Federal e dos Municípios, em conformidade com a pactuação estabelecida na respectiva CIB e, se houver, CIR; ou seja, deixando explícito que cada ente deve ter contribuição para que o serviço seja ofertado com qualidade.

A insatisfação em relação a serviços que estão diretamente ligados a recursos financeiros foi pertinente e evidente nas falas dos usuários, como a insuficiência de transporte "o carro que não tem para levar ele" e o transporte que não tem muito para o médico se locomover" (C19). E isso, acaba dificultando o acesso dos profissionais com maior frequência ao domicílio, haja vista que grande parcela dos domicílios estão localizados na zona rural do município, tendo localidades com distância de até $60 \mathrm{~km}$ da sede "transporte falta, deixa de ser atendida" (C3). O serviço dispõe de apenas um veículo (carro), o que inviabiliza a adequação da realização das visitas domiciliares com maior periodicidade "... a disponibilidade que é pouca, mas acho que são os recursos que não dão" (C11) e "não é por conta do profissional, mas pelo que é repassado pra ele" (U6). Em alguns casos, podendo interferir ou retardar a evolução clínica de alguns pacientes críticos "como não tem periodicidade, ai agente precisa e não vem, ai temos que procurar outra forma" (C13).

A insuficiência ou ausência de material para a realização do trabalho foi uma importante dificuldade citada pelos entrevistados especialmente quanto à carência de medicamentos "deveria ser bem equipado com medicamento no carro" (U1), suplementos alimentares, dietas enterais e materiais básicos de curativos "a sonda que está faltando, nós fizemos foi comprar" (C23). Nota-se por meio de alguns relatos o entendimento da comunidade sobre a ausência de materiais que impossibilita a equipe de dar o suporte adequado no momento necessário "A falta de condições para a equipe trabalhar" (C4).

Na visão dos profissionais a insuficiência de recursos, principalmente quando se refere a transporte e materiais é fator preponderante no serviço, pois dificulta o atendimento completo e de qualidade, visto que a atenção domiciliar realiza alguns procedimentos in loco. "É preciso conversar com o gestor, mostrar a real necessidade pra conseguir" (E5). Em relação ao transporte é notório a insuficiência desse recurso, o que interfere na periodicidade 
das visitas "... os recursos são limitados e às vezes fica difícil você ajudar por conta dessa limitação" (E1); bem como o acompanhamento necessário para cada tipo de paciente "o número excessivo de pacientes não permite uma visita próxima [...] principalmente de pacientes mais graves" (E1). Partindo dessas fragilidades, uma indagação mostra como potencialidade a equipe "... que com o mínimo de condição entra na casa do paciente e consegue fazer um bom atendimento" (E5).

Segundo a gestão municipal, o financiamento é uma das fragilidades encontrada no serviço, justificando que "o recurso do governo federal não aporta a equipe de forma ideal" (G1). Além de ressaltar que as necessidades especiais de alguns pacientes atendidos são onerosas para o cofre público. "Tem muito paciente de oxigênio e é caro" (G2). Expressa que o serviço não dispõe de recursos suficientes para atender a sua demanda, como discorre nessa fala "O SAD não tem recursos suficientes para abarcar o número de pacientes que ele tem" (G2). No entanto, sabe-se que o governo federal contribui com uma parcela para o custeio do serviço, sendo de responsabilidade tripartite a contrapartida para manutenção do programa; como é disposto na portaria 963/2013. Enfatiza-se que além dos pacientes em uso contínuo de oxigênio, existem os que precisam de dietas e suplementos alimentares industrializados.

\section{Domicílio como Espaço de Recuperação}

A abordagem da família como centro da Atenção Primária à Saúde é vista como uma situação prioritária, quando se propõe a reorganização das práticas de saúde voltadas a mesma. Assim, é necessário conhecer as configurações que perpassam a família, a cultura, os arranjos sociais, o contexto inserido, bem como compreender a família como um espaço de produção social (Chapadeiro, Andrade \& Araújo, 2011).

Nessa lógica de pensamento a Política Nacional de Humanização aponta que a assistência no domicílio deve conceber a família em seu espaço social privado e doméstico, respeitando o movimento e a complexidade das relações familiares, preservando os laços afetivos das pessoas e fortalecendo a autoestima (Brasil, 2009). Assim, ajudando a construir ambientes mais saudáveis e favoráveis a recuperação da saúde, além do reconhecimento das potencialidades terapêuticas presentes nas relações familiares, que vão além da tecnologia médica (Brasil 2009).

Os achados são consonantes com percepções encontradas por Mandú et al. (2008) que aponta a visita domiciliar como espaço centrado em ações clínico-educativas, que ocultam a dimensão da necessidade de atuar na determinação social do processo saúde-doença com o objetivo de melhoria da qualidade de vida. "Eu faço o que $a$ equipe manda" (C15).

Entrevistados apontam o domicílio como um espaço de cuidado e recuperação de saúde, identificando-o como potencialidade no cuidado "... em casa a gente tem mais o conforto da gente, liberdade" (U3), "[...] é porque a gente cuida dela direitinho, limpa o quarto dela e tudo" (C18) [...] "porque eu sou praticamente uma enfermeira pra ele"(C22). Autores como Araújo et al. (2000) consideram o domicílio um cenário onde ocorrem as relações sociais geradoras de conflitos e de outros fatores de risco de adoecer, sendo também o local privilegiado para o desenvolvimento de ações de promoção e manutenção da saúde.

Para Vaz (1994) a atenção domiciliar propicia a mesma qualidade oferecida nos hospitais quando se refere a demandas, considerada como uma alternativa que favorece a desconcentração "porque em vez da gente ir ao hospital, o hospital vem até a gente, e isso é maravilho"(C19) e "as vezes o paciente precisa de coisa simples, e não precisa ir para o hospital e a equipe vem"(C2). Por isso, que esse tipo de atenção reflete diretamente no aumento da demanda por assistência; bem como o crescimento populacional e a urbanização, que estimula a explosão do acesso aos serviços com maior frequência (Schramm et al., 2004).

Um fator importante observado nas falas quando se trata de domicílio foi o receio por parte da família ou cuidador de locomover o paciente para as unidades hospitalares e de pronto atendimento quando solicitado pela equipe, demostrando desconfiança no cuidado humanizado e resolutivo. "as pessoas que estão lá não tem a condição de prestar o atendimento que eu tenho com ele aqui" (C4) e "aqui em casa vai ter o conforto o afeto, no hospital não tem essa proximidade" (C13); probabilidade para infecções hospitalares "porque no hospital é diferente da sua casa, o banho é superficial, o paciente se enche de escara, aqui é tudo limpo, não tem bactéria, a higiene é bem feita"(C17); e até piora no prognóstico "Para um paciente sair, levar sol, pegar carro, correr risco, infecção"(C8) e 
"no caso do meu filho, que ele não consegue se locomover, a equipe vir na minha casa é uma maravilha"(C5) e "ele esta no meio da gente é uma coisa mais sossegada, tranquila, mais saudável até"(C11).

Portanto, entendem que o domicílio é um local de aconchego e carinho, onde parentes e amigos têm acesso com facilidade e comodidade. Proporciona segurança, agilidade nos cuidados de higiene do paciente e evita possíveis complicações no quadro, que possivelmente poderiam existir em ambiente hospitalar "porque fica mais em contato com a família"(C18) e "...você sabe lidar com o seu familiar"(C4); além do tempo de evolução da recuperação "eles se recuperam mais rápido, porque as vezes só deles ver agente se sente segura"(C3).

Na percepção dos profissionais da equipe, o domicílio é um espaço íntimo, que a sua inserção deve compreender a dinâmica da vida familiar e dispor de uma atitude de respeito e valorização das características peculiares daquele convívio humano "No hospital ele não tem esse vínculo familiar, e em casa ele tem toda a família, vizinhos, palavra de apoio, então não sobrecarrega só um" (E7). "Quando o paciente estar no seu domicílio, com sua família, na cabeça dele ele, vai se sentir mais aconchegado pelos próprios familiares, se sentir mais aberto para dizer o que sente" (E6). Todavia, os conflitos, as interações e desagregações fazem parte do universo simbólico e particular da família, intervindo diretamente na saúde de seus membros (Brasil, 2012). "O SAD é importante por isso, porque agente consegue desmistificar aquele ambiente hospitalar traduzindo para o domicílio e adequado a ele para que ele consiga sua recuperação" (E5); assim "... é fundamental para a recuperação, porque o paciente não pode se deslocar, porque são pacientes fragilizados, críticos e um paciente desse se deslocando ele esta susceptível a adquirir infecção/sepse" (E4).

Segundo Feuerwerker \& Merhy (2008) alguns pacientes portadores de doenças crônicas apresentaram ampliação da sua autonomia, expondo que o cuidado domiciliar oferece uma perspectiva e possibilidade maior de recuperação do que a internação hospitalar "Acredito que a prevenção terciária de cura e reabilitação é totalmente possível se fazer no seu domicilio, e muitas vezes até melhor do que no hospital; visto que existe inúmeros fatores, como o bem estar do paciente, acredito que eles se sintam bem melhor no ambiente domiciliar, fora que evita contaminação hospitalar....complicações, então o domicilio é uma porta de ferramenta de cura e reabilitação do paciente"(E1).

O estudo de Feuerwerker e Merhy (2008) também mostra resultados significativos de fechamento de feridas e na recuperação motora "... as escaras melhoram" (E6), bem como, grande parte dos procedimentos realizados no hospital podem ser desenvolvidos no ambiente domiciliar, tais como coleta de exames, administração de drogas, infusão de dieta enteral, higienização corporal, oxigenoterapia, curativos, retirada de pontos, dentre outros.

Para alguns autores o diferencial da atenção domiciliar é a possibilidade de diagnóstico e intervenção nas eventuais intercorrências biopsicossociais que estejam interferindo no processo terapêutico (Soerensen, Mendes \& Hayashida, 2004) "...eu posso intervir em várias frentes com a realidade daquela família, ver o que eu posso trabalhar, o tipo de alimento, como é preparado o alimento, postura, como é que ele faz a administração da dieta..." (E2).

A percepção dos gestores quanto ao domicílio se faz importante para o fortalecimento e ascensão desse modo de cuidar "... em casa ele tem apoio" (G2); [...] estar perto da família, tem suporte emocional" (G1). Segundo Soerensen, Mendes e Hayashida (2004) a implantação de mais serviços de atendimento domiciliar provocaria impactos nas ações e assistência à saúde, proporcionando benefícios tanto nos aspectos técnico- financeiros como sociais, psicológicos e físicos. Em uma das falas destaca-se "o paciente tem maior índice de cura e de melhora no prognóstico quando ele tem aquela convivência com os familiares, não ficando isolado no hospital" (G2) e "[..] hospital é um ambiente novo para ele" (G2).

Assim, os gestores apontaram o domicílio como um cenário alternativo de apoio à recuperação a saúde, pensando que o paciente do SAD é susceptível a internações repetitivas e mantido em instituições hospitalares por longo tempo, reduzindo a qualidade de vida.

\section{Atenção Domiciliar Dialogando com a Rede}

Conforme a Portaria no 4.279, de 30/12/2010, a reestruturação do Sistema Único de Saúde, na perspectiva de rede de atenção, é uma estratégia de superação do modo fragmentado de operar a assistência e a gestão em saúde (Brasil, 2010). No Brasil, o modelo de atenção à saúde vem sendo continuamente ajustado para o atendimento 
integral ao usuário, com inclusão e ampliação dos serviços. Para seu desenvolvimento, busca-se horizontalidade nas relações entre pontos de atenção, que se encontram desarticulados (Silva, 2011).

Compreendendo a atenção domiciliar como um ponto de atenção na rede torna-se fundamental a definição da organização política da atenção domiciliar, as atribuições das equipes e das famílias, além da construção de novas relações, mais articuladas e cooperativas, entre os diferentes tipos de equipamentos de saúde (Silva et al., 2010).

Mendes (2011) afirma que a estrutura em Rede tem sido uma forte ferramenta de assegurar ao usuário uma assistência com ações e serviços, de forma contínua e de qualidade. Vimos que a atenção domiciliar precisa dialogar com diversos pontos da rede, com o propósito de fortalecer os vínculos institucionais e dar resolutividade no serviço de saúde, otimizando a assistência e humanizando o cuidado.

Segundo a Portaria $\mathrm{n}^{\circ} 923$ de 27 de maio de 2013 a Atenção Domiciliar deve ser norteada por algumas diretrizes: ser estruturada na perspectiva das Redes de Atenção à Saúde, tendo a atenção básica como ordenadora do cuidado e da ação territorial; estar incorporada ao sistema de regulação, articulando-se com os outros pontos de atenção à saúde e com serviços de retaguarda; ser estruturada de acordo com os princípios de ampliação do acesso, acolhimento, equidade, humanização e integralidade da assistência; estar inserida nas linhas de cuidado por meio de práticas clínicas cuidadoras baseadas nas necessidades do usuário, reduzindo a fragmentação da assistência; adotar modelo de atenção centrado no trabalho de equipes multiprofissionais e interdisciplinares; e estimular a participação ativa dos profissionais de saúde envolvidos, do usuário, da família e do cuidador.

Alguns autores afirmam e resgatam a intrínseca relação da RAS e a busca por um sistema integral, e vislumbram na atenção domiciliar a busca pela integralidade nos sentidos vertical, horizontal e transversal (Brito et al., 2013). Partindo desta lógica, uma atuação dialogada e com foco nas necessidades reais do usuário será mais fácil atender os princípios dos SUS.

A gestão municipal visualiza o serviço de atenção domiciliar na rede como um suporte na assistência, que atende às condições de saúde grave, que podem ser recuperadas no ambiente domiciliar, conforme expressa na fala: "Ele atua para dar assistência ao paciente que não tem mais condição de ficar no hospital, que não tem mais resolução do seu problema" (G2). E isto é norteado em um dos eixos da atenção domiciliar que é a "desospitalização", que proporciona agilidade no processo de alta hospitalar com cuidado contínuo no domicílio (Brasil, 2012). "Além de dar suporte aos pacientes graves que a atenção básica não resolve o problema" (G2).

Destaca-se a importância do SAD na rede porque "ele dispõe de uma equipe multidisciplinar no domicilio, como médico, nutricionista, fisioterapeuta, técnica de enfermagem"... [...] dando mais conforto para o paciente, ao invés do paciente estar internado" (G1).

No tocante a comunicação do SAD com a rede de atenção observou-se na fala de um profissional entrevistado que não existe uma relação de apoio com os demais pontos de atenção (postos de saúde, hospital, Unidade de Pronto Atendimento). "Eu não acredito nessa relação, não existe uma relação boa" [...] com os postos e hospitais não há, porque eles não sabem do papel do $S A D$ " e "[...] encaminham o paciente e pronto, te vira, não existe uma ligação entre eles" (E5). Observou-se no discurso o desconhecimento por parte dos pontos de atenção das competências da atenção domiciliar na rede; bem como a ausência de regulação, referência e contra referencia desses pacientes; tornando mais difícil a comunicação para encaminhamento dos pacientes; sendo explícito a descontinuidade do cuidado e a fragmentação do sistema. Portanto, não contempla uma das diretrizes da atenção domiciliar, que é a sua incorporação no sistema de regulação e a ruptura do cuidado continuado, que deveria potencializar a construção de pontes entre os pontos de atenção e a pessoa, e seu próprio domicílio (Brasil, 2012).

Tasca (2011) fala que a existência de mecanismos de coordenação assistencial por todo o caminho percorrido na atenção facilita o funcionamento da rede e, consequentemente, o fortalecimento das dificuldades enfrentadas no dia a dia, como o fluxo restrito de informação sobre os pacientes entre os pontos de atenção ou falta de responsabilização entre os níveis assistenciais no cuidado ao paciente.

Algumas expressões dos entrevistados dão importância ao diálogo entre os pontos de atenção "é de suma importância o diálogo entre o SAD e a atenção básica, vista que o território de atuação é na comunidade, e cada paciente tem uma história na unidade de saúde" (E1). Entende-se que a assistência deve ser compartilhada, com o objetivo da integralidade no cuidado. 
Salientou-se que o apoio que existe da equipe da atenção básica foi limitado ao empréstimo ou fornecimento de materiais de insumo quando necessário. "...quando chego em qualquer ponto de apoio as meninas acolhem bem agente; quando falta material..." (E7).

Por outro lado, no tocante ao relacionamento do usuário/cuidador/ família com os profissionais da equipe, constatou-se como uma das potencialidades registradas. Como pôde ser identificada em algumas falas: "Pessoal sabe tratar o paciente e falar o que pode ser feito, o tratamento, é muito bom..." (U17); [...] "quando minha mãe precisou vieram e fizeram tudo que deveria ser feito" (U19).

O relacionamento estabelecido entre profissionais de saúde e usuários é visto como um desafio para a reorganização do serviço de saúde, sendo primordial para a plena implementação do SUS. Embora se tenha um sistema respaldado em leis, com status de política de Estado, a sua efetivação e concretização também depende das relações estabelecidas entre os trabalhadores e os usuários (Schimith et al., 2011).

Para alguns autores, a mudança do processo de trabalho em saúde só é atingida se houver a reflexão e compreensão de cada profissional sobre o modo de produzir saúde, modificando a sua forma de agir na relação com o usuário (Esmeraldo et al., 2009). "São meus amigos, porque a gente conversa..." (U3); [...] "e ajudam bastante" (U1); “...sempre que preciso de alguma coisa vêm” (C11).

O Sistema Único de Saúde (SUS), em todos os níveis de atenção, é orientado por diretrizes que valorizam práticas em saúde voltadas aos direitos humanos (Delfino et al., 2012).

Portanto, recomenda-se que o vínculo do profissional é fator importante para gerar confiança tanto da família como do usuário nas condutas realizadas, bem como na adesão do tratamento no tempo determinado. Por isso a sua importância no apoio da execução do plano terapêutico, por meio do compartilhamento de saberes do cotidiano e realidade vivenciada (Carvalho, 2009).

Logo, os usuários externaram uma relação de afeto com os trabalhadores, sentimento evidente nos discursos:

"Bem aconchegante, familiar, amorosa" (C18); "A gente faz tudo para agradar" (C16); "A gente é parceiro em prol do paciente" (C26) "[...] atencioso com o paciente" (C8).

Assim, inferimos que a proposta de vínculo idealizada em referenciais teóricos foi capturada pelos sujeitos da pesquisa. O que implica de forma positiva no resultado de uma assistência e cuidado realizado com responsabilidade, afeto e vínculo, realçando o profissionalismo da equipe em questão.

\section{Considerações Finais}

A percepção de diversos olhares sobre o serviço de atenção domiciliar do município de Maranguape permitiu a reflexão quanto à qualidade do serviço, levando ao tensionamento de questões relevantes sobre a atenção domiciliar e reconhecendo a assistência domiciliar como um fortalecimento e continuidade do cuidado.

Entendendo que as práticas do SAD são realizadas no próprio domicílio, observou-se que é de extrema importância a conexão e a efetivação da atenção integral. O acolhimento humanizado é o primeiro contato com a família, cuidador e/ou usuário, e esta etapa deve apresentar respeito, valorização, compreensão, paciência e afeto, visto que, a casa é o espaço privado do usuário, na qual ele permite a entrada da equipe de saúde.

Assim, sugiro diálogos de aproximação e geração de confiança na equipe, com visitas em espaços curtos, que possam gerar uma teia de apoio e corresponsabilidade, partindo da inclusão de todos no compartilhamento dos casos.

Compreendendo as fragilidades encontradas na atenção domiciliar nota-se, que o financiamento é o nó crítico para execução do serviço com maior qualidade; a deficiência na estrutura ofertada dificulta cada vez mais a implementação do SUS, que visa garantir o acesso com integralidade. Portanto, os gestores diretamente ligados ao financiamento e execução dos recursos devem ser melhor sensibilizados a discussões sobre a responsabilidade da administração dos recursos público; conhecimento dos incentivos de custeio repassados, e as responsabilidades de cada ente interfederativo, de forma que estimule e garanta os princípios da universalidade, integralidade e equidade 
do SUS em todos os níveis de atenção. Desta forma, evitando justificativas das fragilidades existentes baseado nos recursos de custeio oriundo apenas do ente federal.

Na categoria do diálogo da atenção domiciliar com a rede de atenção à saúde notamos a importância das relações entre os pontos; reforçando que os pontos de atenção precisam se comunicar para melhor direcionar o paciente nos níveis de atenção. Percebemos ainda a fragilidade deste fazer, o que dificulta a agilidade no atendimento, as referências e contra referências, consequentemente a recuperação de saúde do paciente. Sugerimos a gestão como mediadora do diálogo entre o SAD e os pontos de atenção.

O reconhecimento da importância do domicílio com um espaço de recuperação e manutenção de saúde pelos entrevistados é de suma importância, visto que, a partir do momento que se cria vínculos e corresponsabilidades, as metas são mais fáceis de serem atingidas. Por isso, o contexto domiciliar deve ser trabalhado de forma peculiar com o reconhecimento das diferenças e necessidades de cada usuário ou família, considerando a expressiva dimensão do cuidado domiciliar como um relevante aspecto para a atenção humanizada.

Portanto, os gestores responsáveis pela adesão e implantação dos programas de melhoria da assistência à saúde devem buscar estratégias inovadoras de cuidar. A implementação da atenção domiciliar como estratégia inovadora tensiona reflexão sobre concepções de saúde e de vida que sustentam a organização das práticas no domicílio. É necessário que se considerem diversos elementos como a integralidade do cuidado, a racionalidade econômicofinanceira, os sujeitos do cuidado e a articulação com os demais serviços de saúde (Silva et al., 2010)

O estudo permitiu ainda, compreender que a avaliação dos programas de saúde estimula e é capaz de modificar o arranjo das políticas e do fazer saúde. Portanto, é pertinente a necessidade de um olhar mais crítico dos profissionais e da gestão de ferramentas adequadas para incorporação e efetivação de novas técnicas que fortaleça a operacionalização do programa na rede de saúde.

Com base no que interpretamos, sugerimos a realização de espaços de co-gestão da equipe multiprofissional de forma planejada e contínua com monitoramento dos indicadores e ações, a fim de aproximar e socializar as dificuldades e potencialidades encontradas diariamente no serviço. Apontamos ainda, momentos de matriciamento entre as categorias profissionais e os demais pontos de atenção (domicílio, unidade básica, hospitais, Upas, dentre outros), na busca de produzir conhecimento inter profissional para alinhamento das discussões e problematização do cotidiano, ampliando a capacidade de intervenções coletivas nos territórios; além de fortalecer o papel da atenção domiciliar na rede de saúde.

Acreditamos que o programa melhor em casa ainda não está sendo capaz de reverter o cenário de desospitalização e de dar resolutividade de alguns problemas existentes na atenção básica, embora se visualize um grande potencial na ampliação do acesso a usuários incapazes de locomoção e descentralização do sistema de saúde.

Assim, podemos inferir que esta pesquisa contribui em seus achados para provocar gestores e profissionais quanto ao modo de fazer atenção domiciliar, no tocante a otimização e alocação de recursos públicos, assim como levá-los a refletir sobre o modo de cuidar e gerenciar saúde. Pensar na reorganização do serviço e melhorias das condições de trabalho dos profissionais, e reconhecer as fragilidades, que sinalizam intervenções para superá-las; partindo da relevância que é a atenção domiciliar no cuidado continuado. Pesquisas nessa direção contribuiriam com o grande desafio de garantir uma saúde de qualidade, equânime e integral numa rede que se encontra fragilizada; além de subsidiar novas práticas que possam dar resolutividade concreta a lacunas encontradas no atual Sistema Único de Saúde.

Considerando que a Residência Integrada em Saúde com ênfase em Saúde Coletiva, visa formar sanitaristas para atuar frente às necessidades de saúde da população nos diversos momentos do processo saúde-doença; e por se tratar de um processo vivo, de formação em serviço, a construção dessa pesquisa colabora para incentivar trabalhadores, gestores e usuários na reconstrução e adequação às ferramentas de cuidado em saúde. 


\section{Referências}

Andreazzi, M. F. S., \& Baptista, D. 2007. Reflexões sobre modelos de financiamento de assistência domiciliar em saúde e avaliação de custos.

Araújo, M. R. N., Sampaio, L. C., Carneiro, M. L. M., \& Sena, R. R. (2000). Saúde da Família cuidado no domicilio. Rev. Bras. Enferm. Vol.53 no.spe Brasília Dec.

Brasil. (2009). Ministério da Saúde. Secretaria de Atenção à Saúde. Política Nacional de Humanização da Atenção e Gestão do SUS. O Humaniza SUS na atenção básica / Ministério da Saúde-Brasília. 40 p. il. color. - (Série B. Textos Básicos de Saúde).

Brasil. (2009). Política Nacional de Humanização da Atenção e Gestão do SUS: acolhimento e classificação de risco nos serviços de urgência. Brasília. (Serie B. Textos Básicos de Saúde).

Brasil. (2010). Portaria GM/MS 4.279, de 30 de dezembro de 2010. Estabelece diretrizes para a organização da Rede de Atenção à Saúde no âmbito do Sistema Único de Saúde (SUS). Brasília: Ministério da Saúde.

Brasil. (2013). Portaria GM/MS no 963, de 27 de maio de 2013. Redefine a Atenção Domiciliar no âmbito do Sistema Único de Saúde (SUS). Brasília: Ministério da Saúde.

Brasil. (2013). Ministério da Saúde. Secretaria de Atenção a Saúde. Departamento de Atenção Básica. Caderno de atenção domiciliar / Ministério da Saúde, Secretaria de Atenção a Saúde, Departamento de Atenção Básica. Brasília: Ministério da Saúde.

Brito, M. J. M. et al. (2013). Atenção domiciliar na estruturação da rede de atenção à saúde: trilhando os caminhos da integralidade. Esc. Anna Nery, Rio de Janeiro, v. 17, n. 4, p. 603-610.

Carvalho, L. C. (2009). A disputa de planos de cuidado na atenção domiciliar. Rio de Janeiro: UFRJ.

Cotta, R. M. M. (2005). A satisfação dos usuários do Programa Saúde da Família: avaliando o cuidado em saúde. Sci. med. v.15 n.4.

Chapadeiro, C. A., Andrade, H. O., Araújo, M. R. N. (2011). A família como foco da atenção primária à saúde. Belo Horizonte: Nescon/UFMG.

Delfino, M. R. R., Karnopp, Z. M. P., Rosa, M. P., \& Pasin, R. R. (2012). Repercussões do processo de ensinar-aprender em serviços de saúde na qualidade de vida dos usuários. Trab Educ Saúde. 10(2), 315-33.

Esmeraldo, G. V., Oliveira, L. C., Sousa, K. M. N., Araújo, M. A. M., Esmeraldo Filho, C. E., \& Viana, E. M. N. (2009). Análise do acolhimento na estratégia de saúde da família sob a perspectiva do usuário. Rev APS. 12(2), 119-30.

Franco, T. B., Bueno, W. S., Merhy, E. E. (2000). O acolhimento e os processos de trabalho em saúde: o caso de Betim (MG). Cad. Saúde Pública, Rio de Janeiro, 15(2), 345-352.

Feurwerker, L. C. M., Merhy, E. E. (2008). A contribuição da atenção domiciliar para a configuração de redes substitutivas de saúde: desinstitucionalização e transformação de práticas. Rev Panam Salud Publica. 24(3): 180-8.

Instituto Brasileiro de Geografia e Estatística. Censo demográfico. (2010). Rio de Janeiro. Disponível em: http://www.ibge.gov.br/home/. Acesso em: 10 setembro de maio 2016.

Mandú, E. N. T., Gaíva, M. A. M., Silva, M. A., \& Silva, A. M. N. (2008).Visita domiciliária sob o olhar de usuários do programa saúde da família. Jan-Mar; 17(1), 131-40.

Maynart, W. H. C., Maria, C. S., Albuquerque, M. Z., Brêda, J., \& Jorge, S. (2014). A escuta qualificada e o acolhimento na atenção psicossocial. Acta Paul Enferm. 27(4), 300-3.

Mendes, E. V. (2011). As redes de atenção à saúde. Brasília, DF: Organização Pan-Americana da Saúde.

Orlandi, E. P. (2001). Análise de Discurso: princípios e procedimentos. Campinas, SP: Pontes.

Puccini, P. T., \& Cecílioo, L. C. (2004). A humanização dos serviços e o direito à saúde. Cad. Saúde Pública, Rio de Janeiro. 20(5), 1342-1353, set-out. 
Roa, R. R., Oliveira, A. C. D., Savassi, L. C. M., Souza, L. C., \& Dias, R. B. (2009). Abordagem centrada nas pessoas. Ver. Bras. Med. Fam. Comunidade. 4(16), 245- 59

Rocha, P. M., et al. (2008). Avaliação do Programa Saúde da Família em municípios do Nordeste brasileiro: velhos e novos desafios. Cad Saúde Pública. v24, supl.1.

Schramm, J. M. A., et al. (2004). Transição epidemiológica e o estudo de carga de doença no Brasil. Ciênc. saúde coletiva [online]. 9(4), 897-908. ISSN 1413-8123.

Schweller, M. (2014). O ensino de empatia no curso de graduação em medicina. Campinas-SP: [ s.n.]. Tese (Doutorado) - Universidade Estadual de Campinas.

Silva, K. L. et al. (2010). Atenção domiciliar como mudança do modelo tecnoassistencial. R. Saúde Pública, São Paulo. 44(1), 166-176.

Silva, S. F. (2011). Organização de redes regionalizadas e integradas de atenção à saúde: desafios do Sistema Único de Saúde (Brasil). Ciênc Saúde Coletiva. 16(6), 2753-62

Schimith, M. D., Simon, B. S., Brêtas, A. C. P., \& Budó, M. L. D. (2011). Relações entre profissionais de saúde e usuários durante as práticas em saúde. Trab Educ Saúde. 9(3), 479-503

Souza, W. S. (2008). A temática da humanização na saúde: alguns apontamentos para debate. InterfaceComunicação, Saúde, Educação, 12(25), 327-338, abr./jun.

Soerensen, A. A., Mendes, I. A., \& Hayashida, M. (2004). Atendimento Domiciliar: Análise de um serviço privado. Rev. RENE. Fortaleza. 5(2), 86-92, jul./dez.

Tasca, R. (2011). Redes e regionalização em saúde no Brasil e na Itália: lições aprendidas e contribuições para o debate. Brasília: Opas.

Vaz, J. C. (1994). Assistência domiciliar à saúde. Dicas - idéias para a ação municipal. Secretaria Municipal de Saúde. Santos. SP, n.8, mar.

\section{APENDICE I:}

\section{ENTREVISTA SEMI ESTRUTURADA COM USUÁRIOS DO SERVIÇO}

DE ATENÇÃO DOMICILIAR DO MUNICÍPIO DE MARANGUAPE - CE

\section{IDENTIFICAÇÃO}

1. Iniciais do nome: 2. idade: 3. Sexo: ( ) M ( ) F

4. Profissão:

6. Escolaridade Atual:

\section{QUESTÕES NORTEADORAS PARA USUÁRIOS}

1. O que é Acolhimento humanizado?

2. O que você entende por ser bem acolhido?

3. Quais as dificuldades encontradas na adesão ao serviço?

4. Como é a sua relação com a equipe multiprofissional?

5. Quais as fragilidades que você identifica no serviço?

6. Você acredita que o domicílio seja um espaço importante para a recuperação da saúde?

7. Quais potencialidades que você identifica na atenção domiciliar? 
APENDICE II:

ENTREVISTA SEMI ESTRUTURADA COM PROFISSIONAIS DO SERVIÇO

DE ATENÇÃO DOMICILIAR DO MUNICÍPIO DE MARANGUAPE - CE

IDENTIFICAÇÃO

1. Iniciais do nome

2. idade:

3. Sexo: ( ) M ( ) F

4. Profissão:

6. Escolaridade Atual:

\section{QUESTÕES NORTEADORAS}

1. O que é Acolhimento humanizado?

2. O que você entende por Acolher bem?

3. Quais as dificuldades você observa para adesão ao serviço?

4. Como é a sua relação com a equipe multiprofissional?

5. Como é a relação do SAD com os demais pontos de atenção?

6. Quais as fragilidades que você identifica no serviço?

7. Você acredita que o domicílio seja um espaço importante para a recuperação da saúde?

8. Quais potencialidades que você identifica na atenção domiciliar?

APENDICE III:

ENTREVISTA SEMI ESTRUTURADA COM GESTORES DO SERVIÇO

DE ATENÇÃO DOMICILIAR DO MUNICÍPIO DE MARANGUAPE - CE

IDENTIFICAÇÃO

1. Iniciais do nome

2. idade:

3. Sexo: ( ) M ( ) F

4. Profissão:

6. Escolaridade Atual:

\section{QUESTÕES NORTEADORAS}

1. O que é Acolhimento humanizado?

2. O que você entende por acolher bem?

3. Quais as dificuldades você observa para adesão ao serviço?

4. Como é a relação da gestão com a equipe do SAD?

5. Como você vê o SAD na rede de atenção?

6. Quais as fragilidades que você observa no serviço?

7. Você acredita que o domicílio seja um espaço importante para a recuperação da saúde?

8. Quais potencialidades você identifica na atenção domiciliar? 


\section{Sobre os Autores}

Cleovânia Fontenele dos Santos é nutricionista, Residente em Saúde Coletiva pela Escola de Saúde Pública do Ceará/ ESP-CE, Fortaleza (CE), Brasil.

Jadson Franco (MsC) é psicólogo, Mestre em Educação Profissional Em Saúde pela Fundação Osvaldo Cruz, Rio de Janeiro, Brasil. 